\title{
Fracturing political commitment to implement vaccine mandates
}

- Cite as: CMAJ 2021 November 29;193:E1819. doi: 10.1503/cmaj.1095975

Posted on cmajnews.com on November 12, 2021

$\mathbf{P}$ olitical will to implement vaccine mandates is ebbing in some provinces despite expert advisors supporting the measures.

The Ontario government recently announced it would not mandate COVID19 vaccinations for hospital workers, citing concerns about potential staffing shortages. Instead, the government will leave it up to hospitals to implement their own policies.

The Ontario Hospital Association decried the decision, noting that "Ontario cannot afford to let its guard down," given the pandemic's devastating toll on health systems and human life.

Six Ontario hospitals had active outbreaks at the time of the announcement.

According to Premier Doug Ford, a "small number of outbreaks" does not justify implementing a province-wide mandate that could lead to the departures of "tens of thousands of health workers" - a claim that critics say is a vast overestimate.

Ontario officials pointed to recent cancellations of surgeries in British Columbia following the suspensions of more than 4000 health care workers who were not fully vaccinated.

However, according to Ontario's COVID19 science advisory table, outbreaks of COVID-19 are more likely to cause staffing problems than vaccine mandates.

So far, hospitals that have implemented their own COVID-19 vaccination requirements have reported low rates of noncompliance.

Meanwhile, Quebec has walked back its mandate for all health care workers to be fully vaccinated against COVID-19 by November 15. Now, the policy will apply only to new staff.

According to health minister Christian Dubé, requiring COVID-19 vaccinations for all health workers could have led to 500 service reductions or reorganizations.

Quebec and Ontario have not mandated COVID-19 vaccines for teachers or staff in public schools, either.

Quebec officials said they will not require the shots, as $90 \%$ of teachers and staff are already vaccinated.

Once COVID-19 vaccines are approved for children, Ontario public schools will likely host vaccine clinics.

However, Ontario education minister Stephen Lecce said that requiring staff in public schools to be vaccinated could result in 50000 terminations - a questionable claim considering that the government reported that closer to 46000 school workers are not yet fully vaccinated, and that count includes an undetermined number of workers who are partially vaccinated, have medical exemptions, or have not declared their status because they're on leave.

According to the Toronto District School Board, most workers who did not declare their vaccine status were occasional staff, the vast majority of whom were not currently working for the board.

Staffing concerns haven't dissuaded other jurisdictions from moving forward on vaccine mandates.

British Columbia plans to expand its vaccine mandate for health workers to include doctors and dentists practising outside the public health care system.

New Brunswick has mandated all civil servants, staff in schools and childcare facilities, and health care workers to be fully vaccinated by November 19 .

And Alberta Health Services will require all health workers to be fully vaccinated by the end of November.

Beyond Canada, New Zealand will soon mandate COVID-19 vaccinations in a wider range of settings where workers have close contact with the public, including restaurants, bars, gyms, and hair salons. The policy will require about $40 \%$ of all workers in the country to be fully vaccinated.

Abigail Cukier, Hamilton, Ont., with files from Lauren Vogel, CMAJ

Content licence: This is an Open Access article distributed in accordance with the terms of the Creative Commons Attribution (CC BY-NC-ND 4.0) licence, which permits use, distribution and reproduction in any medium, provided that the original publication is properly cited, the use is noncommercial (i.e., research or educational use), and no modifications or adaptations are made. See: https://creativecommons.org/ licenses/by-nc-nd/4.0/ 